\title{
PERFORMANCE OF PEDIATRIC INDEX OF MORTALITY-2 IN A PEDIATRIC INTENSIVE CARE UNIT OF A TERTIARY CARE HOSPITAL OF NEPAL
}

\author{
Dhungana SP1, Panta PP², Shrestha SK', Shrestha $\boldsymbol{S}^{1}$
}

${ }^{1}$ Department of Pediatrics, ${ }^{2}$ Department of Community Medicine, Nepal Medical College Teaching Hospital, Attarkhel, Gokarneshwor-8, Kathmandu, Nepal.

\begin{abstract}
Various scoring system have been developed and are becoming essential part of Pediatric and other critical care units. The Pediatric department wants to introduce Pediatric Index of Mortality-2 (PIM 2) as a predictive scoring system in Pediatric critical care unit of Nepal Medical College Teaching Hospital (NMCTH). This was a prospective cohort study done in Pediatric Intensive Care Unit (PICU) of NMCTH. Study was done from August 2017 to December 2018. All cases admitted in ICU were taken consecutively from term newborn to 14 yrs of age. PIM 2 scoring system was done in all patients. PIM 2 performed well in terms of discrimination with area under curve for PIM 2 score was 0.809 with $95 \%$ Confidence Interval of 0.0709 to 0.910 and Standard Error of 0.051 . Good calibration was observed across deciles of risk as measured by Hosmer-Lemeshow goodness of fit test with P value of 0.163, chi-square value of 11.752 (8). Mortality observed in our PICU was $28.4 \%$ with standardized mortality ratio of 1 . PIM 2 scoring system performed well in our PICU.
\end{abstract}

\section{KEYWORDS}

Pediatric index of mortality, pediatric intensive care unit, mortality, Nepal

\section{CORRESPONDING AUTHOR}

Dr. Sangita Puree Dhungana,

Lecturer,

Department of Pediatrics,

Nepal Medical College Teaching Hospital,

Attarkhel, Gokarneshwor-8, Kathmandu, Nepal.

Email: sangita17.dhungana@hotmail.com. 


\section{INTRODUCTION}

Scoring systems that predict the risk of mortality for children in an intensive care unit (ICU) are needed for the evaluation of the effectiveness of pediatric intensive care..$^{1,2}$.

The primary purpose of intensive care is to provide treatment to patients with life threatening physiologic dysfunction by using therapies that can only be provided in the ICU or to monitor and observe patients perceived to be at significant risk of dying. ${ }^{3}$ Monitoring of the seriously ill patients for early detection of life threatening events and for assessment of response to therapeutic measures is an essential ingredient of this practice. ${ }^{4,5,6,7}$.

Measuring the severity of disease and prognosis in patients in the ICU is very important because the quality of patient care across ICUs cannot be compared without some objective index of disease severity. Predictive scoring systems can provide a stable foundation for research into the therapeutic efforts and the economics of care in the ICU, and predictive scoring systems may plot the course of critical illness and help clinical decision making. ${ }^{8}$ Scoring system are usually used to predict prognosis. Various scoring systems have been developing in past years. In PICUs, worldwide, pediatric risk of mortality (PRISM) ${ }^{9}$ first used in America and Pediatric Index of Mortality (PIM) ${ }^{10}$ in Europe are being used widely. PIM $2^{11}$ and PRISM $3^{12}$ are the newer versions of these scoring systems. When performances of scores are compared both have shown similar performance in Pakistan, ${ }^{13}$ India, ${ }^{14}$ Hongkong, ${ }^{15}$ China,,${ }^{16}$ Netherland ${ }^{17}$ and UK. ${ }^{18}$

High cost of attaining the software has limited the use of PRISM 3 even in developed nations whereas PIM 2 based calculators and statistical formulas are freely available as a web based calculator. ${ }^{19}$ This PIM 2 tool will be used to assess severity in the patients admitted with heterogeneous group of disease in Pediatric ICU.

\section{MATERIALS AND METHODS}

This is a prospective cohort study done in PICU of NMCTH. Study was done from August 2017 to December 2018. Ethical clearance was taken from Institutional Review Committee of NMCTH. All cases admitted in ICU were taken consecutively from term newborn to 14 years of age. Patient admitted in a state of continuous cardio-pulmonary resuscitation who never achieved stable vitals for at least 2 hours, fixed and dilated pupil secondary to brain death during ICU admission and premature babies $<37$ weeks were excluded from the study. The guardians were explained in detail about the nature of the study. An informed consent was taken prior to carrying out the study.

Data collection included: age, sex, admission type (elective, from ward, from ER), referring specialty, diagnosis, failing organ systems, length of stay, outcome and other variables as per PIM 2 scoring system. All items of PIM 2 were collected at the admission or within $1 \mathrm{hr}$. Observed ICU mortality was collected.

PIM 2 included Systolic Blood Pressure, Pupillary reaction, $\mathrm{PaO} 2$ and $\mathrm{FiO} 2$, base excess in arterial or capillary blood. Mechanical ventilation within first hr in ICU, elective admission to ICU, recovery from surgery or procedure is the main reason for ICU admission, admitted following cardiac bypass. High risk diagnosis were cardiac arrest before ICU admission, Severe Combined Immunodeficiency, leukemia/lymphoma after $1^{\text {st }}$ induction, spontaneous cerebral hemorrhage, cardiomyopathy/myocarditis, Hypoplastic Left Heart syndrome, HIV infection, liver failure, neuro-degenerative disorder or none. Low risk diagnosis were asthma, bronchiolitis/ respiratory distress/apnoea, croup, obstructive sleep apnoea, diabeticketoacidosis or none.

PIM 2-based mortality risk was calculated based on the regression equations on a web based calculator (https://qxmd.com/calculate/calculator_368/pim2). The overall performance of scoring system was assessed by Standardised Mortality Rate (SMR), i.e. comparing observed and expected PICU deaths in the total group. Statistical analysis of the calibration of PIM 2 was carried out using the Hosmer and Lemeshow goodness-of-fit test ${ }^{20}$ for deciles of mortality risk, based on the ranked mortality risks of all patients for scoring system. Discrimination was assessed by construction of receiver operating characteristic (ROC) curve, ${ }^{21}$ in which sensitivity is plotted against (1-specificity), the area under the curve being the overall summary measure of discriminatory performance. Statistical analysis was carried out with SPSS version 20.

\section{RESULTS}

Total number of patients admitted to our PICU during the study period was 143 however only 127 were included in our study as 16 met the exclusion criteria. Table 1 shows baseline characteristics of study patients. Mean age was 35 months (minimum 1 month to maximum of 168 months) and 60.6\% were less than one year of age. There were 85 male (66.9\%) and 42 female (33.1\%). Maximum admissions were from the ward $81(63.8 \%)$, emergency 38 (29.9\%), and from other hospitals 8 (6.3\%). Mean duration of PICU stay was 6.85 days with minimum of 1 day and maximum of 29 days. Major causes leading to PICU admission were sepsis/septic shock 43 (33.9\%), respiratory diseases $32(25.2 \%)$, neurological diseases 18 (14.2\%) and cardiovascular diseases 12 (9.4\%). Observed mortality was 36 (28.4\%). Severe malnutrition also showed high probability of mortality in our patients though statistically not significant. Use of vasopressor and mechanical ventilation was significantly associated with mortality in our study. 
Table 1: Baseline characteristics of study patients.

\begin{tabular}{|c|c|c|c|c|}
\hline Variables & All Patients & Survivors n (\%) & Non-survivors n (\%) & $\mathrm{p}$ value \\
\hline \multicolumn{5}{|l|}{ Age } \\
\hline 0-30 days & 26 & $20(76.9 \%)$ & $6(23.1 \%)$ & \multirow{5}{*}{0.218} \\
\hline 1-12 months & 52 & $33(63.5)$ & $19(36.5 \%)$ & \\
\hline 13months-5years & 21 & $18(85.7 \%)$ & $3(14.3 \%)$ & \\
\hline $5-10$ years & 9 & $5(55.5 \%)$ & $4(44.5 \%)$ & \\
\hline $10-14$ years & 19 & $15(78.9 \%)$ & $4(21.1 \%)$ & \\
\hline \multicolumn{5}{|l|}{ Sex } \\
\hline Male & 85 & $61(71.7 \%)$ & $24(28.3 \%)$ & \multirow[t]{2}{*}{0.968} \\
\hline Female & 42 & $30(71.4 \%)$ & $12(28.6 \%)$ & \\
\hline \multicolumn{5}{|l|}{ Admission from } \\
\hline Emergency & 38 & $22(57.9 \%)$ & $16(42.1 \%)$ & \multirow{3}{*}{0.049} \\
\hline Ward & 81 & $64(79.1 \%)$ & $17(20.9 \%)$ & \\
\hline Other hospital & 8 & $5(62.5 \%)$ & $3(37.5 \%)$ & \\
\hline \multicolumn{5}{|l|}{ Diagnosis } \\
\hline Sepsis & 43 & $22(51.2 \%)$ & $21(48.8 \%)$ & \multirow{8}{*}{0.009} \\
\hline Respiratory diseases & 32 & $26(81.3 \%)$ & $6(18.7 \%)$ & \\
\hline CNS & 18 & $16(88.9 \%)$ & $2(11.1 \%)$ & \\
\hline CVS & 12 & $11(91.7 \%)$ & $1(8.3 \%)$ & \\
\hline Post surgical & 10 & $8(80 \%)$ & $2(20 \%)$ & \\
\hline GI/Liver & 7 & $5(71.4 \%)$ & $2(28.6 \%)$ & \\
\hline Hematological & 3 & $1(33.3 \%)$ & $2(66.7 \%)$ & \\
\hline Renal & 2 & $2(100 \%)$ & $0(0 \%)$ & \\
\hline \multicolumn{5}{|l|}{ Weight for age } \\
\hline$<-1$ SD below mean & 50 & $35(70 \%)$ & $15(30 \%)$ & \multirow{4}{*}{0.248} \\
\hline$>-1$ to $<-2$ SD below mean & 42 & $32(76.2 \%)$ & $10(23.8 \%)$ & \\
\hline$>-2 S D$ to $<-3 S D$ below mean & 26 & $20(76.9 \%)$ & $6(23.1 \%)$ & \\
\hline >-3SD below mean & 9 & $4(44.4 \%)$ & $5(55.6 \%)$ & \\
\hline \multicolumn{5}{|l|}{ Weight for height } \\
\hline$<-1 S D$ below mean & 64 & $48(75 \%)$ & $16(30 \%)$ & \multirow{4}{*}{0.824} \\
\hline$>-1$ to $<-2$ SD below mean & 42 & $28(66.7 \%)$ & $14(33.3 \%)$ & \\
\hline$>-2 \mathrm{SD}$ to $<-3 \mathrm{SD}$ below mean & 18 & $13(72.3 \%)$ & $5(27.7 \%)$ & \\
\hline >-3SD below mean & 3 & $2(66.7 \%)$ & $1(33.3 \%)$ & \\
\hline \multicolumn{5}{|l|}{ Ventilated } \\
\hline Yes & 36 & $10(27.8 \%)$ & $26(72.2 \%)$ & \multirow[t]{2}{*}{$<0.0001$} \\
\hline No & 91 & $81(89.1 \%)$ & $10(10.9 \%)$ & \\
\hline \multicolumn{5}{|l|}{ Vasopressors use } \\
\hline Yes & 43 & $15(34.9 \%)$ & $28(65.1 \%)$ & \multirow[t]{2}{*}{$<0.0001$} \\
\hline No & 84 & $76(90.5 \%)$ & $8(9.5 \%)$ & \\
\hline
\end{tabular}

Good calibration of PIM 2 score was observed across deciles of risk as measured by Hosmer-Lemeshow goodness of fit test with $p$ value of 0.163 , chi-square value of 11.752 with degree of freedom of 8 as shown in Table 2.
Hosmer-Lemeshow goodness-of-fit test across PIM 2 risk categories and Standardized Mortality Ratio showed good calibration of PIM 2 score. It showed $p$ value of 0.163 , chi-square value of 5.123 with degree of freedom of 3. 


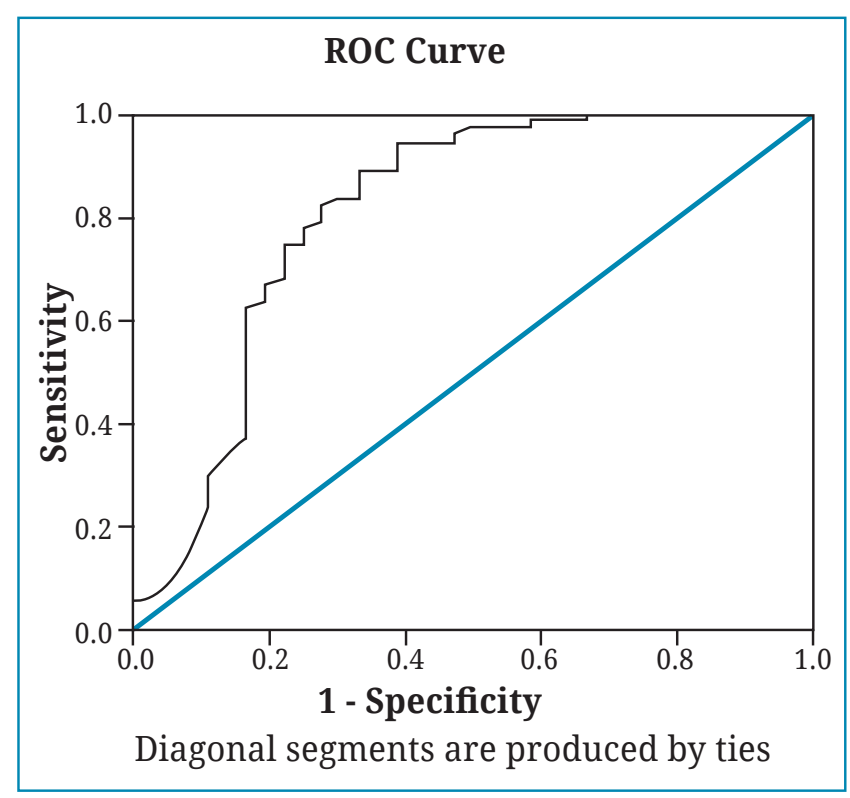

Fig.1: ROC curve for PIM 2 score

Fig. 1 shows the area under the ROC curve for PIM 2. The area under curve for PIM 2 score was 0.809 with $95 \%$ CI of 0.0709 to 0.910 and Standard Error of 0.051 .

\section{DISCUSSION}

This study included 127 patients admitted in PICU of NMCTH to evaluate the performance of PIM 2. Our results showed good performance of PIM 2 scoring system in terms of calibration and discrimination when applied to heterogeneous group of patients. Mean age of patients were comparable with other studies. Mean age was 35 months in our study, it was 42 months $^{22}$, 45 months ${ }^{23}$ and 44 months $^{24}$ in other studies.

Most of our cases were infants $(60.6 \%)$ and male (66.9\%). Majority of cases were male (60\%) in other study also with no significant difference in mortality. ${ }^{22}$ Mean duration of PICU stay was 6.85 days which is similar to that of study done in Japan ${ }^{24}$ 6.7 days and Africa ${ }^{29} 6$ days. Major causes for PICU admission were sepsis/septic shock $33.9 \%$ and respiratory diseases $25.2 \%$. Case mix in developing countries is different from units where the score was developed. Sepsis/severe sepsis were common cause of admission in India also ${ }^{28}$.

Mortality observed in our PICU was $28.4 \%$, similar to that of Pakistan $28.7 \%,{ }^{13}$ and near to that reported from India $32 \% .{ }^{14}$ Our mortality is also similar to

Table 2: Hosmer-Lemeshow goodness of fit test across Pediatric Index of Mortality-2 deciles and Standardized Mortality Ratio (SMR).

\begin{tabular}{|c|c|c|c|c|c|}
\hline \multirow{2}{*}{ PIM II } & \multicolumn{2}{|c|}{ Survival } & \multicolumn{2}{|c|}{ Death } & \multirow{2}{*}{ SMR } \\
\hline & Observed & Expected & Observed & Expected & \\
\hline 1 & 1 & 1.706 & 12 & 11.294 & 1.06 \\
\hline 2 & 4 & 4.917 & 9 & 8.083 & 1.12 \\
\hline 3 & 10 & 7.547 & 3 & 5.453 & 0.55 \\
\hline 4 & 9 & 9.281 & 4 & 3.719 & 1.07 \\
\hline 5 & 11 & 10.847 & 2 & 2.153 & 0.92 \\
\hline 6 & 13 & 11.366 & 0 & 1.634 & 0 \\
\hline 7 & 12 & 11.676 & 1 & 1.324 & 0.76 \\
\hline 8 & 11 & 11.962 & 2 & 1.038 & 1.93 \\
\hline 9 & 12 & 12.115 & 1 & 0.885 & 1.13 \\
\hline 10 & 8 & 9.582 & 2 & 0.418 & 4.78 \\
\hline Total & 91 & 90.999 & 36 & 36.001 & 1 \\
\hline
\end{tabular}

Table 3: Hosmer-Lemeshow goodness of fit test across Pediatric Index of Mortality-2 risk categories and Standardized Mortality Ratio (SMR).

\begin{tabular}{|lccccc|}
\hline & \multicolumn{2}{c}{ Survival } & \multicolumn{2}{c}{ Death } & SMR \\
$0-1 \%$ & Observed & Expected & Observed & Expected & \\
$1-5 \%$ & 0 & 0.654 & 11 & 10.346 & 1.06 \\
$5-15 \%$ & 2 & 2.162 & 7 & 6.838 & 1.03 \\
$15-30 \%$ & 18 & 16.543 & 9 & 10.457 & 0.86 \\
$>30 \%$ & 65 & 64.814 & 8 & 8.186 & 0.98 \\
Total & 6 & 6.828 & 1 & 0.172 & 5.8 \\
\hline
\end{tabular}


mortality observed in other developing countries like India 28\%. ${ }^{28}$ Lower mortality in unit like $2.6 \%$ in Argentina and Japan,,23,24 5.5\% in Barbados, ${ }^{25}$ $14.23 \%$ in Brazil, ${ }^{22} 15 \%$ in Iran $^{26}$ are also reported. Some unit reported mortality as high as $46.2 \%$ in India, ${ }^{27}$ which is due to late referral to their unit. Severe malnutrition had higher mortality in our patients though statistically not significant. Severe malnutrition was associated with higher mortality in other study also reported from India ${ }^{14}$. Use of vasopressor and mechanical ventilation was significantly associated with mortality in our study. Presence of shock, GCS $<8$ and mechanical ventilation were significantly associated with mortality in study done in India by Gandhi et al. ${ }^{27}$

Good discrimination was observed in our study with area under ROC curve of 0.809 with $95 \%$ CI of 0.709 to 0.910 and SE of 0.051 . Similar discriminatory performance with area under curve of 0.80 to 0.90 was reported in studies done in Pakistan, ${ }^{13}$ Barbados, ${ }^{25}$ India,${ }^{27}$ and South Africa. ${ }^{30}$ Just acceptable discrimination with area under ROC curve of 0.7-0.8 was reported in study from Brazil, ${ }^{22}$ Iran, ${ }^{26}$ India, ${ }^{28}$ Africa, ${ }^{29}$ and Egypt. ${ }^{31}$ Very good discrimination with area under ROC curve of $>0.9$ was reported in study from Argentina, ${ }^{23}$ Japan, ${ }^{24}$ and Croatia. ${ }^{32}$

PIM 2 scoring system in our ICU showed good calibration observed across deciles of risk as measured by Hosmer-Lemeshow goodness of fit test with $P$ value of 0.163 , chi-square value of 11.752 with degree of freedom of 8 . Good calibration was also observed in study done in India ${ }^{28}$. Unsatisfactory calibration was reported in study done in Argentina. ${ }^{23}$ Authors have explained this could be due to low no of deaths in their unit.

Standardized mortality rate was 1 in our study when applied to heterogeneous group of patients admitted in our unit which is similar to that reported in study from Brazil. ${ }^{22}$ Most other studies from developing countries have reported the under prediction of deaths in their setup, with the Standardized mortality ratio and its 95\% CI being more than $1 .^{14,26}$ Overestimation of death may be due to better performance of that unit while underestimation seen may be due to difference in case mix, physiology, quality of care and resources in terms of equipments and human resources. ${ }^{33}$

In conclusion, PIM 2 performed well in our unit to predict death. It can be done easily within 1 hour of admission to prognosticate patients which will be useful in counseling patients. Calibration across mortality risk strata was also good. We can use PIM 2 scoring system in our PICU. A larger multi-centric study with large number of sample is needed to validate PIM 2 in Nepalese PICUs.

\section{REFERENCES}

1. Earle MJ, Natera OM, Zaslavsky A, et al. Outcome of pediatric intensive care at six centers in Mexico and Ecuador. Crit Care Med 1997; 25: 1462-7. https://doi.org/10.1097/00003246-199709000-00011 PMID:9295818.

2. Schnitzler E. Pediatric intensive care in Argentina. Crit Care Med 1993; 2: 403-4.

3. Pollack MM,Getson PR, Ruttimann UE et al. Efficiency of intensive care. A comparative analysis of eight pediatric intensive care units. I Am Med Assoc 1987; 258: 1481-6. https://doi.org/10.1001/ jama.1987.03400110063026

4. Ozer EA, Kizilgunesler A, Sarioglu B, Halicioglu O, Sutcuoglu S, Yaprak I. The comparison of PRISM and PIM scoring systems for mortality risk in infantile intensive care. J Trop Pediatr 2004; 50: 334-8. https://doi.org/10.1093/tropej/50.6.334.

5. Pollack MM, Ruttimann UE, Getson PR. Accurate prediction of the outcome of pediatric intensive care, A new quantitative method. $N$ Engl $J$ Med 1987; 316: 134-9. https://doi.org/10.1056/ NEJM198701153160304.

6. Keeler EB, Rubenstein LV, Kahn KL et al. Hospital characteristics and quality of care. J Am Med Assoc 1992; 268: 1709-14. https://doi.org/10.1001/ jama.1992.03490130097037.

7. Brenan TA, Herbert LE, Laird LM et al. Hospital characteristics associated with adverse events and substandard care. J Am Med Assoc 1991; 265: 3265-9. https://doi.org/10.1001/jama.1991.03460240061028
8. Seneff M, Knaus WA. Predicting patient outcome from intensive care: a guide to APACHE, MPM, SAPS, PRISM, and other prognostic scoring systems. Intensive Care Med. 1990; 5: 33-52.

9. Pollack MM, Ruttimann UE, Getson PR. Pediatric risk of mortality (PRISM) score. Crit Care Med 1988; 16: $1110-6$.

10. Shann F, Pearson G, Slater A, Wilkinson K. Paediatric index of mortality (PIM): a mortality prediction model for children in intensive care. Intensive Care Med 1997; 23: 201-7. https://doi. org/10.1007/s001340050317.

11. Slater A, Shann F, Pearson G, for the PIM Study Group: PIM2: A revised version of the paediatric index of mortality. Intensive Care Med 2003; 29: 278-85. https://doi.org/10.1007/s00134-002-1601-2.

12. Pollack MM, Patel KM, Ruttimann UE. PRISM III: An update Pediatric Risk of Mortality score. Crit Care Med 1996; 24: 743-52.

13. Qureshi AU, Ali AS, Ahmad TM. Comparison of three prognostic scores (PRISM, PELOD and PIM 2) at pediatric intensive care unit under Pakistani circumstances. J Ayub Med Coll Abbottabad. 2007; 19: 49-53.

14. Thukral A, Lodha R, Irshad M, Arora NK. Performance of Pediatric Risk of Mortality (PRISM), Pediatric Index of Mortality (PIM) and PIM 2 in a pediatric intensive care unit in a developing country. Pediatr Crit Care Med 2006; 7: 356-61. https://doi. org/10.1097/01.PCC.0000227105.20897.89. 
15. Choi KM, Ng DK, Wong SF et al. Assessment of the Pediatric Index of Mortality (PIM) and the Pediatric Risk of Mortality (PRISM) III score for prediction of mortality in a paediatric intensive care unit in Hong Kong. Hong Kong Med J 2005; 11: 97-103.

16. Qiu J, Lu X, Wang K, Zhu Y, Zuo C, Xiao Z. Comparison of the pediatric risk of mortality, pediatric index of mortality, and pediatric index of mortality 2 models in a pediatric intensive care unit in China: A validation study. Medicine 2017; 96: https://doi. org/10.1097/MD.0000000000006431.

17. Gemke RJ, van Vught JA. Scoring systems in pediatric intensive care: PRISM III versus PIM. Intensive Care Med 2002; 28: 204-7. https://doi. org/10.1007/s00134-001-1185-2.

18. Brady AR, Harrison D, Black S et al. Assessment and optimization of mortality prediction tools for admissions to pediatric intensive care in the United Kingdom. Pediatrics 2006; 117: 733-42. https://doi. org/10.1542/peds.2005-1853.

19. https://qxmd.com/calculate/calculator_368/pim2.

20. Hosmer Jr DW, Lemeshow S, Sturdivant RX. Applied logistic regression. John Wiley \& Sons; 2013. https:// doi.org/10.1002/9781118548387.

21. Hanley JA, McNeil BJ. The meaning and use of the area under a receiver operating characteristic (ROC) curve. Radiology 1982; 143: 29-36. https://doi. org/10.1148/radiology.143.1.7063747.

22. Lima Netto A, Muniz VM, Zandonade E et al. Performance of the Pediatric Index of Mortality 2 in a pediatric intensive care unit. Rev Bras Terapia Intensiva 2014; 26: 44-50. https://doi. org/10.5935/0103-507X.20140007

23. Eulmesekian PG, Pérez A, Minces PG, Ferrero H. Validation of pediatric index of mortality 2 (PIM2) in a single pediatric intensive care unit of Argentina. Pediatr Crit Care Med 2007; 8: 54-7. https://doi. org/10.1097/01.pcc.0000256619.78382.93.

24. Imamura T, Nakagawa S, Goldman RD, Fujiwara T. Validation of pediatric index of mortality 2 (PIM2) in a single pediatric intensive care unit in Japan. Intensive Care Med 2012; 38: 649-54.

25. Hariharan S, Krishnamurthy K, Grannum D. Validation of pediatric index of mortality-2 scoring system in a pediatric intensive care unit, Barbados.
J Trop Pediatr 2010; 57: 9-13. https://doi.org/10.1093/ tropej/fmq031.

26. Salamati P, Talaee S, Eghbalkhah A, Chaman R, Mokhtari Z, Azarshahin M. Validation of pediatric index of mortality-2 scoring system in a single pediatric intensive care unit in Iran. Iranian $J$ Pediatr 2012; 22: 481-6.

27. Gandhi J, Sangareddi S, Varadarajan P, Suresh S. Pediatric index of mortality 2 score as an outcome predictor in pediatric Intensive Care Unit in India. Indian J Crit Care Med 2013; 17: 288-91. https://doi. org/10.4103/0972-5229.120320.

28. Sankar J, Singh A, Sankar MJ, Joghee S, Dewangan S, Dubey N. Pediatric index of mortality and PIM2 scores have good calibration in a large cohort of children from a developing country. Biomed Resc Int'l 2014; 2014: 907871. doi: 10.1155/2014/907871.

29. Bekhit OE, Algameel AA, Eldash HH. Application of pediatric index of mortality version 2: score in pediatric intensive care unit in an African developing country. Pan Afr Med J 2014; 17. https:// doi:10.11604/pamj.2014.17.185.2818.

30. Solomon LJ, Morrow BM, Argent AC. Paediatric Index of Mortality scores: An evaluation of function in the paediatric intensive care unit of the Red Cross War Memorial Children's Hospital. South Afr J Crit Care 2014; 30: 8-13. https://doi.org/10.7196/ SAJCC.166.

31. Labib Youssef MR, Mosleh H, Labib JR. Assessment of the performance of the Pediatric Index of Mortality 2 (PIM 2) among Egyptian pediatric patients admitted to the intensive care. Egypt Pediatr Assoc Gazette 2014; 62: 65-71.

32. Mestrovic J, Kardum G, Polic B, Omazic A, Stricevic L, Sustic A. Applicability of the Australian and New Zealand Paediatric Intensive Care Registry diagnostic codes and Paediatric Index of Mortality 2 scoring system in a Croatian paediatric intensive care unit. Euro J Pediatr 2005; 164: 783-4. https:// doi.org/10.1007/s00431-005-1755-3.

33. Raghavendra BY, Patil VD, Bellad RM, Mahanthshetti NS. A prospective cohort study for the comparison of two prognostic scores-PRISM 3 and PIM 2 in a paediatric intensive care unit. J Evol Med Dent Sci 2014; 3: 10954-67. https://doi.org/10.14260/ jemds/2014/3430. 